\title{
Health-Risk Transition and 8-Year Hypertension Incidence in a Nationwide Thai Cohort Study
}

\author{
Prasutr Thawornchaisit, MD, $\mathrm{PhD}^{1}$, Ferdinandus de Looze, MBBS, $\mathrm{MSc}^{2}$, Christopher M Reid, $\mathrm{PhD}^{3}$, Sam-ang \\ Seubsman, $\mathrm{PhD}^{4}$ \& Adrian Sleigh, $\mathrm{MD}^{5}$ \\ ${ }^{1}$ Department of Medical Services, Ministry of Public Health, Thailand \\ ${ }^{2}$ School of Medicine, University of Queensland, Australia \\ ${ }^{3}$ School of Public Health and Preventive Medicine, Monash University, Australia \\ ${ }^{4}$ School of Human Ecology, Sukhothai Thammathirat Open University, Thailand \\ ${ }^{5}$ National Centre for Epidemiology and Population Health, Research School of Population Health, ANU College \\ of Health and Medicine, The Australian National University, Australia \\ Correspondence: Prasutr Thawornchaisit, Department of Medical Services, Ministry of Public Health, Thailand; \\ 88/23 Tiwanon Road, Amphoe Muang, Nonthaburi 11000, Thailand. Tel: 11-66-2590-6381; Fax \\ 11-66-2965-9863. E-mail: prasutt@yahoo.com
}

Received: November 8, 2017 Accepted: December 20, 2017 Online Published: January 8, 2018

doi:10.5539/gjhs.v10n2p99 URL: https://doi.org/10.5539/gjhs.v10n2p99

\begin{abstract}
Objective: Rapid economic growth is transforming Thailand into a middle-income country. Also emerging are chronic diseases particularly hypertension, diabetes mellitus and kidney disease. There are few studies of the incidence of hypertension. We analyse the effect on 8-year incidence of hypertension of transitional health-risk factors including demography, socioeconomic status (SES), body mass index (BMI), sedentariness, physical activity, underlying diseases, personal behaviours, food, fruit and vegetable consumption.
\end{abstract}

Design and Methods: Health-risk factors and their effects on the incidence of hypertension were evaluated prospectively in the national Thai Cohort Study from 2005 to 2013. All data were derived from 40,548 Sukhothai Thammathirat Open University students returning mail-based questionnaire surveys in both 2005 and 2013. Adjusted relative risks of association between each risk factor and incidence of hypertension were calculated after controlling for confounding factors.

Results: In Thailand, the 8-year incidence of hypertension was 5.1\% (men 7.1\%, women 3.6\%). Hypertension was associated with ageing, higher BMI, diabetes mellitus, chronic kidney disease, high lipids, SES, lower education level, lower household asset, physical inactivity, smoking, instant food intake and soft drink. Sex, having a partner, urbanization and sedentary habits had no influence on hypertension.

Conclusion: In Thailand, hypertension is becoming a serious risk factor for chronic disease with a wide array of associations with modern life. As Thailand's socio-economy develops the health-risk transition will further impact on population health. Thais should be encouraged by government policy to consume less instant food, maintain normal BMI, increased physical activity, stop smoking and consume less soft drink.

Keywords: hypertension, socioeconomic status, body mass index, physical activity, underlying diseases, smoking, Thailand

\section{Introduction}

Hypertension is a global public health challenge contributing significantly to the population burden of cardiovascular disease (CVD) and kidney disease. This is important because CVD is the leading cause of death in the world. Globally, more than 55 million people died in 2013 and $32 \%$ of these deaths (17 million) were attributable to CVD (GBD 2013 Mortality and Causes of Death Collaborator, 2015). The majority of these CVD deaths were a consequence of ischemic heart disease (IHD) or cerebrovascular disease together with associated hypertension (Huangfu et al., 2017). Worldwide, one in four adults had hypertension in 2000 and one in three will be affected by 2025 (Kearney et al., 2005). The global prevalence of hypertension in adults is already 1 billion and rising (Cifkova, Fodor, \& Wohlfahrt, 2016), causing more than ten million deaths annually (Collaborators et al., 2015). Hypertension is now the leading global health risk for world mortality (WHO, 2017). 
In Thailand, National Health Examination Surveys this century revealed that the prevalence of hypertension in adults was $22 \%$ in 2004 and $21.5 \%$ in 2009 (Aekplakorn et al., 2008; Aekplakorn et al., 2012), a stable rate somewhat below that for the South Asia (approximately 27\%) (Neupane et al., 2014). The leading causes of death in Thailand are cancer (19\%) followed by CVD, particularly ischemic heart disease (12\%) and strokes (10\%) (WorldAtlas, 2017). Hypertension and diabetes are risk factors for CVD deaths for Thais. Indeed, in a large national Thai Cohort Study (TCS) observing the risk transition since 2004, population attributable fractions for CVD deaths in Thailand were calculated as 16\% for hypertension and 10\% for diabetes (Zhao, Kelly, et al., 2015).

There are few studies reporting directly measured incidence of hypertension in Thailand (Thawornchaisit et al., 2013c; Vathesatogkit et al., 2012). Our Thai Cohort Study (TCS), ongoing since 2005, is focused on the transition in health risks accompanying modernization. Here we report the impacts on population health, investigating demography, socio-economy, lifestyles and other health risks associated with hypertension during 8 years of follow-up. At baseline in 2005, the mostly young cohort had an overall prevalence of hypertension of $4.6 \%$ (Thawornchaisit et al., 2013a). Over the 4-year follow up from 2005 to 2009 the cumulative incidence of hypertension was 3.5\% (Thawornchaisit et al., 2013c). Now we have measured the 8-year incidence of hypertension and its associations and effects and we are able to report on a larger time sample of the cohort transitions that are operating to produce CVD in Thailand.

\section{Methods}

\subsection{Study Population and Data}

The Thai Cohort Study (TCS) commenced in 2005 and was comprised of 87151 distance-learning students enrolled at Sukhothai Thammathirat Open University (STOU). In comparison with the Thai population, the STOU student body and the TCS members were comparable for social geography and socio-economic status (Seubsman, Yiengprugsawan, Sleigh, \& the Thai Cohort Study, 2012) but differed in age. The student body and cohort members were younger with $56.2 \%$ and $51.5 \%$ respectively in the $21-30$ year age range compared to $23.9 \%$ in the general Thai population and fewer were older than 50 years $(1.2 \%$ and $2 \%$ respectively) compared with $24.7 \%$. In addition, the STOU student body and TCS members tended to have a higher education level than the general population.

TCS baseline data were generated from a 20-page mail-out questionnaire which included questions on demography, socio-economic status (SES), personal health (chronic kidney disease, diabetes mellitus, high blood lipids, high blood pressure, stroke, various cancers, goitre, epilepsy, asthma, arthritis, chronic bronchitis and depression). As well there were questions on hearing, vision, dental impairment, use of health services, transport, injury, social networks, personal well-being, health-related behaviour and family background. Baseline data have been published (Seubsman et al., 2012; Sleigh, Seubsman, \& Bain, 2008). The number of cohort members participating at 4-year follow up was $60569(70 \%)$ in 2009 and there were 42785 responders $(49 \%)$ in 2013 at 8 -year follow up.

\subsection{Incident Hypertension}

Incident hypertension was defined as being normotensive in 2005 and self-reporting doctor diagnosed hypertension in 2013. Hypertension incidence was the binary dependent variable for analyses and the person-time denominator included all individuals at risk-those 40548 (94.8\%) of the 42785 participants with 8-year longitudinal data (2005 to 2013) who were negative for hypertension at the start (2005).

\subsection{Independent Variables}

The independent variables that were available for analysis included age, sex, marital status, urbanization, socio-economic status (SES - income, household assets, and education), body mass index (BMI), and underlying diseases (diabetes mellitus, high lipids and kidney disease). Other variables we analysed included sedentary habits (screen time, sitting time and house-work or gardening), other lifestyle factors (physical exercise, tobacco smoking, alcohol consumption, soy bean consumption, fruit and vegetable intake and soft drinks) and food preferences (Western, roast, smoked, instant, deep fried).

Age was divided into three categories $(\leq 30.31-40,>40)$. Marital status was defined as married/living with a partner or single. Urbanization status was classified in childhood (aged 12 years) and at baseline (2005) producing 4 lifelong categories: ruralites (RR), urbanizers (RU), de-urbanizers (UR) and urbanites (UU). Education level was grouped into three categories (High school, Diploma, University. Personal monthly income was divided into four categories in baht. In 2005, one US dollar was equivalent to 42 baht. Household assets were classified into three categories (low, medium, high in baht).

Asian cut-offs following guidelines of the International Obesity Task Force (Kanazawa et al., 2005): underweight (BMI < 18.5), normal $(18.5 \leq \mathrm{BMI}<23.0)$, overweight $(23 \leq \mathrm{BMI}<25.00)$, or obese $(\mathrm{BMI} \geq 25)$ were used to 
calculate and categorize BMI.

Screen time and sitting time (hours/day) were proxies for sedentariness. Incidental exercise (frequency of housework or gardening), was categorised into 4 groups: $\leq 3$ times per month; 1-2 times per week; 3-4 times per week; most days. Various forms of physical activity (at least 20 minutes of mild, moderate or strenuous exercise, 10 minutes or more walking sessions) were also included and recorded using 4-item ordinal categories.

An overall measure of planned physical activity was calculated separately at both the baseline and the 8-year mark. This was based on the cohort members reporting the number of sessions per week of strenuous and moderate exercise for at least 20 minutes, and of walking for at least 10 minutes. We weighted the measure as follows: ( $2 \times$ strenuous $+1 \times$ moderate $+1 \times$ walking) sessions per week, weighting based on the recommendation of the International Physical Activity Questionnaire and the Active Australia Survey as used in other analyses of cohort data (Australian Institute of Health and Welfare, 2003; Banks, Lim, Seubsman, Bain, \& Sleigh, 2011). Finally, for each individual, the 'overall measures' of weekly exercise for 2005 and 2013 were added and then averaged by dividing by 2 , creating a longitudinal measure of planned physical activity (LPPA).

Smoking was self-reported and grouped into never, ex-smoker or current smoker. Alcohol consumption had four categories: never, ex-drinker, occasional drinker or current-drinker. Foods that may influence hypertension (deep fried, instant, roast or smoked, soybean products and soft drinks) and Western-style fast foods were assessed for consumption frequency. Fruit and vegetable consumption were recorded as standard serves eaten per day.

\subsection{Statistical Analyses}

We performed all analyses using SPSS software. Hypertension incidence and 95\% CI were calculated for each value of each categorical variable. For statistical inference, all $p$ values were two tailed and significance was set at $5 \%$.

In a large study of an uncommon disease (incidence less than 10\%) relative risks (RRs) can be accurately estimated as odds ratios (ORs) (Webb \& Bain, 2011). Accordingly, for each risk variable, the RR and 95\% CI were estimated using logistic regression to calculate the bivariate OR for hypertension. Adjusted RRs (aRRs) were estimated by multivariate logistic regression ORs controlled for confounding by age, sex, marital status, socioeconomic status (SES), BMI, underlying diseases and personal behaviours (cigarette smoking and alcohol drinking). A co-variable was included in the multivariable model if bivariate analysis had indicated a statistically significant association with incidence of hypertension. Some variables were included because earlier analyses reported elsewhere had shown a significant or substantial association with hypertension.

\section{Results}

\subsection{Baseline Characteristics}

Overall, 42785 of the original cohort participated in the 8-year follow up. Of these cohort members 40548 had self-reported as normotension in 2005 are shown in Table 1. The mean age at baseline of these longitudinal participants was 32 years and there were more females than males (56\%vs $44 \%)$. The highest proportion of participants resided in the Central regions and North-eastern and the lowest proportion lived in the East. Sixty three percent of the participants lived in urban areas. More than half of participants had a higher education attainment than high school and their monthly incomes were lower than 10000 baht. The distribution of household assets of participants was quite similar with a slightly higher proportion of participants in the low category.

\subsection{Incidence and Risks of Hypertension}

In Thailand, the incidence of self-reported doctor diagnosed hypertension in adults was $5.1 \%$ and the rate in men was approximately twice the corresponding rate in women ( $7.1 \%$ vs $3.6 \%$; Table 2$)$. The incidence of hypertension increased with age. Sex, marriage or having a partner, and personal income had no influence on the risk hypertension. However, the risk of hypertension decreased with increased level of educational attainment and household assets.

The risk of hypertension increased with an increased BMI. Planned physical activity, averaged across the 8-year follow-up, was a protective factor. The higher LPPA categories ( $\geq 8-14$ and $\geq 15$ sessions/week) were associated incrementally with lower incidence of hypertension, but the trend is not statistically significant. Hypertension risk increased in those who had diabetes mellitus, high blood lipids or kidney disease. Current smokers had a higher risk of developing hypertension than non-smokers. However alcohol drinking had no influence on the risk of incident hypertension. Hypertension directly associated with frequency of instant food consumption and drinking soft drinks. Fruit and vegetable intake had no influence on hypertension. 
Table 1. Characteristics of 40548 normotensive participants at the 2005 Thai Cohort Study baseline

\begin{tabular}{|c|c|c|}
\hline \multirow{2}{*}{ Factor } & \multicolumn{2}{|c|}{ Participants } \\
\hline & $\mathrm{n}$ & percent \\
\hline \multicolumn{3}{|l|}{ Demographic data } \\
\hline Participants & 40548 & \\
\hline Age (y) mean & 32.10 & \\
\hline (SD) & $(8.2)$ & \\
\hline \multicolumn{3}{|l|}{ Age group } \\
\hline$\leq 30 \mathrm{y}$ & 19682 & 48.5 \\
\hline $31-40 y$ & 14206 & 35.0 \\
\hline$>40 \mathrm{y}$ & 6660 & 16.4 \\
\hline \multicolumn{3}{|l|}{ Sex } \\
\hline Male & 17769 & 43.8 \\
\hline Female & 22779 & 56.2 \\
\hline \multicolumn{3}{|l|}{ Married/partnered } \\
\hline No & 20586 & 52.1 \\
\hline Yes & 18946 & 47.9 \\
\hline \multicolumn{3}{|l|}{ Regions } \\
\hline Bangkok & 6522 & 16.2 \\
\hline Central & 9630 & 23.9 \\
\hline North & 8125 & 20.0 \\
\hline North-east & 8580 & 21.3 \\
\hline East & 2348 & 5.8 \\
\hline South & 5122 & 12.6 \\
\hline \multicolumn{3}{|l|}{ Urbanization status $^{a}$} \\
\hline Rural-rural (RR) & 2508 & 19.1 \\
\hline Rural-urban (RU) & 3782 & 28.9 \\
\hline Urban-rural (UR) & 2346 & 17.9 \\
\hline Urban-urban (UU) & 4461 & 34.1 \\
\hline \multicolumn{3}{|l|}{ Socioeconomic status } \\
\hline \multicolumn{3}{|l|}{ Education level } \\
\hline High school & 17837 & 44.1 \\
\hline Diploma & 10862 & 26.9 \\
\hline University & 11753 & 29.1 \\
\hline \multicolumn{3}{|c|}{ Personal monthly income (baht) ${ }^{b}$} \\
\hline$\leq 7000$ & 14663 & 36.9 \\
\hline $7001-10000$ & 9214 & 23.2 \\
\hline $10001-20000$ & 11107 & 27.9 \\
\hline$>20000$ & 4785 & 12.0 \\
\hline \multicolumn{3}{|c|}{ Household assets $^{\mathrm{e}}$ (baht) ${ }^{\mathrm{d}}$} \\
\hline Low & 15133 & 37.5 \\
\hline Medium & 12865 & 31.9 \\
\hline High & 12387 & 30.7 \\
\hline
\end{tabular}

${ }^{a}$ Location of residence (rural, R, or urban, U) before and in 2005. The values showed only participants who moved their residences within 5 years;

${ }^{\mathrm{b}}$ At the time of the survey in 2009, US $\$ 1=31$ Thai baht;

${ }^{\mathrm{e}}$ Replacement value in Thai baht, categorized into three groups: low $\leq 30,000$, medium 30,001-60,000 and high $>60,000$. 
Table 2. Hypertension incidence and association with risk factors in participants

\begin{tabular}{|c|c|c|c|c|}
\hline & HT(n) & $\mathrm{I}^{\mathrm{a}} \%(95 \% \mathrm{CI})$ & $\mathrm{aRR}^{\mathrm{b}}(95 \% \mathrm{CI})$ & \\
\hline Participants & 1958 & $5.1(4.9-5.3)$ & & \\
\hline \multicolumn{5}{|l|}{ Demography } \\
\hline \multicolumn{5}{|l|}{ Age group } \\
\hline$\leq 30 \mathrm{y}$ & 356 & $1.9(1.7-2.1)$ & 1 & \\
\hline $31-40 y$ & 752 & $5.6(5.2-6.0)$ & $2.43(2.06-2.86)$ & \\
\hline$>40 \mathrm{y}$ & 850 & $13.7(12.8-14.6)$ & $5.39(4.45-6.53)$ & \\
\hline P-trend & & & & $<0.0001$ \\
\hline \multicolumn{5}{|l|}{ Sex } \\
\hline Female & 769 & $3.6(3.3-3.8)$ & 1 & \\
\hline Male & 1189 & $7.1(6.7-7.5)$ & $1.11(0.96-1.28)$ & \\
\hline \multicolumn{5}{|c|}{ Socio-economic status } \\
\hline \multicolumn{5}{|c|}{ Education level } \\
\hline University & 580 & $5.1(4.7-5.5)$ & 1 & \\
\hline Diploma & 445 & $4.3(3.9-4.7)$ & $1.04(0.89-1.21)$ & \\
\hline High school & 923 & $5.6(5.2-5.9)$ & $1.17(1.02-1.34)$ & \\
\hline P-trend & & & & $<0.05$ \\
\hline \multicolumn{5}{|c|}{ Household asset } \\
\hline High & 836 & $7.1(6.6-7.5)$ & 1 & \\
\hline Medium & 604 & $4.9(4.6-5.3)$ & $1.67(1.02-1.33)$ & \\
\hline Low & 509 & $3.6(3.3-3.9)$ & $1.15(1.0-1.34)$ & \\
\hline P-trend & & & & $<0.0001$ \\
\hline \multicolumn{5}{|c|}{ BMI classification ${ }^{c}$} \\
\hline \multicolumn{5}{|l|}{$(\mathrm{BMI}<18.5)$} \\
\hline $\begin{array}{l}\text { Normal } \\
(18.5 \leq \mathrm{BMI}\end{array}$ & 571 & $2.8(2.5-3.0)$ & 1 & \\
\hline \multicolumn{5}{|c|}{$(23 \leq \mathrm{BMI}<25)$} \\
\hline \multicolumn{5}{|l|}{$(\mathrm{BMI} \geq 25)$} \\
\hline P-trend & & & & $<0.0001$ \\
\hline \multicolumn{5}{|c|}{ Physical activities } \\
\hline \multicolumn{5}{|c|}{$\begin{array}{l}\text { Weighted total sessions exercise-related physical } \\
\text { activity (average between } 2005 \text { and 2013) }\end{array}$} \\
\hline $0-7 \mathrm{ses} / \mathrm{w}^{\mathrm{d}}$ & 552 & $5.2(4.8-5.7)$ & 1 & \\
\hline $8-14 \mathrm{ses} / \mathrm{w}$ & 653 & $5.0(4.6-5.3)$ & $0.86(0.75-1.0)$ & \\
\hline$\geq 15 \mathrm{ses} / \mathrm{w}$ & 495 & $4.9(4.5-5.3)$ & $0.77(0.65-0.92)$ & \\
\hline P-trend & & & & 0.237 \\
\hline
\end{tabular}

${ }^{\mathrm{a}}$ Incidence of Hypertension;

${ }^{\mathrm{b}}$ Adjusted relative risks were calculated from multi-variable logistic regression models of hypertension adjusted for age, sex, marital status, socioeconomic status (exclude type of house), BMI classification, sedentary habits, physical activities, underlying diseases and personal behaviours;

${ }^{\mathrm{c}}$ Asian standard BMI classification;

${ }^{\mathrm{d}}$ Sessions/week . 
Table 2. (continued...)

\begin{tabular}{|c|c|c|c|c|}
\hline & HT(n) & $\mathrm{I}^{\mathrm{a}} \%(95 \% \mathrm{CI})$ & $\mathrm{aRR}^{\mathrm{b}}(95 \% \mathrm{CI})$ & \\
\hline \multicolumn{5}{|c|}{ Underlying diseases } \\
\hline \multicolumn{5}{|c|}{ Diabetes mellitus (type1\&2) } \\
\hline No & 1889 & $5.0(4.8-5.18)$ & 1 & \\
\hline Yes & 69 & $22.0(17.4-26.7)$ & $1.61(1.14-2.27)$ & \\
\hline \multicolumn{5}{|l|}{ High lipids } \\
\hline No & 1484 & $4.3(4.07-4.5)$ & 1 & \\
\hline Yes & 474 & $12.7(11.6-13.8)$ & $1.4(1.23-1.62)$ & \\
\hline \multicolumn{5}{|l|}{ Kidney disease } \\
\hline No & 1875 & $5.0(4.8-5.2)$ & 1 & \\
\hline Yes & 83 & $8.9(7.1-10.7)$ & $1.74(1.32-2.3)$ & \\
\hline \multicolumn{5}{|c|}{ Personal behaviours } \\
\hline \multicolumn{5}{|l|}{ Smoking status } \\
\hline Never & 1127 & $4.0(3.8-4.3)$ & 1 & \\
\hline Ex-smoker & 510 & $7.9(7.3-8.6)$ & $1.01(0.87-1.17)$ & \\
\hline Cur-smoker ${ }^{\mathrm{c}}$ & 254 & $8.5(7.5-9.5)$ & $1.33(1.10-1.6)$ & \\
\hline P-trend & & & & $<0.0001$ \\
\hline \multicolumn{5}{|l|}{ Drinking status } \\
\hline Never & 419 & $3.9(3.6-4.3)$ & 1 & \\
\hline Ex-drinker & 192 & $6.1(5.3-7.0)$ & $1.19(0.95-1.49)$ & \\
\hline Occ- drinker ${ }^{\mathrm{d}}$ & 1125 & $5.0(4.7-5.3)$ & $1.1(0.96-1.28)$ & \\
\hline Reg- drinker ${ }^{\mathrm{e}}$ & 198 & $11.3(9.8-12.8)$ & $0.83(0.66-1.06)$ & \\
\hline P-trend & & & & $<0.0001$ \\
\hline \multicolumn{5}{|c|}{ Food consumption habit } \\
\hline \multicolumn{5}{|l|}{ Instant food } \\
\hline$<1$ time $/ \mathrm{m}$ & 502 & $6.3(5.7-6.8)$ & 1 & \\
\hline $1-3$ times $/ \mathrm{m}$ & 793 & $5.2(4.8-5.5)$ & $1.03(0.9-1.19)$ & \\
\hline $1-2$ times/wk & 400 & $4.3(3.8-4.7)$ & $1.14(1.0-1.35)$ & \\
\hline 3-6 times/wk & 209 & $4.6(4.0-5.2)$ & $1.24(1.0-1.53)$ & \\
\hline$\geq 1$ times $/ \mathrm{d}$ & 40 & $4.9(3.4-6.4)$ & $1.45(1.0-2.2)$ & \\
\hline P-trend & & & & $<0.0001$ \\
\hline \multicolumn{5}{|l|}{ Soft drink } \\
\hline$<1$ time $/ \mathrm{m}$ & 521 & $5.0(4.6-5.5)$ & 1 & \\
\hline 1-3 times $/ \mathrm{m}$ & 547 & $4.9(4.5-5.3)$ & $1.01(0.9-1.17)$ & \\
\hline 1-2 times/wk & 433 & $5.1(4.7-5.6)$ & $1.17(1.0-1.37)$ & \\
\hline 3-6 times/wk & 317 & $5.5(4.9-6.1)$ & $1.34(1.12-1.6)$ & \\
\hline$\geq 1$ times $/ \mathrm{d}$ & 123 & $5.4(4.4-6.3)$ & $1.34(1.12-1.60)$ & \\
\hline P-trend & & & & 0.192 \\
\hline
\end{tabular}

${ }^{\mathrm{a}}$ Incidence of Hypertension;

${ }^{\mathrm{b}}$ Adjusted relative risks were calculated from multi-variable logistic regression models of hypertension adjusted for age, sex, marital status, socioeconomic status (exclude type of house), BMI classification, sedentary habits, physical activities, underlying diseases and personal behaviours;

${ }^{\mathrm{c}}$ Current-smoker;

${ }^{\mathrm{d}}$ Occasional drinker;

${ }^{\mathrm{e}}$ Regular drinker. 


\section{Discussion}

This is the first large national cohort study to investigate the incidence of hypertension and its risks in Thai adults. The 8-year follow up from 2005 to 2013 of participants initially normotensive revealed a cumulative incidence of hypertension over this period of $5.1 \%$ with the rate in men about twice that in women. Ageing, obesity or underlying diseases (particularly diabetes, high blood lipids and chronic kidney disease) were strongly associated with a higher incidence of hypertension while education attainment and household assets were inversely related to the incidence of hypertension. Cigarette smoking, instant food and soft drinks consumption had a moderate effect on hypertension incidence but planned physical activity averaging 8 or more sessions per week over the 8 -year period reduced the incidence of hypertension. Sex and marital or partner status had no influence on hypertension.

The health risks for hypertension in Thailand now are changing rapidly as the population transitions to a middle income with an ageing demographic profile (Apinonkul, Soonthorndhada, Vapattanawong, Jagger, \& Aekplakorn, 2016; Sleigh et al., 2008). Obesity is rising (Aekplakorn et al., 2014; Seubsman et al., 2010) and related chronic diseases, especially CVD (Putadechakum, 2014), diabetes (Aekplakorn et al., 2011; Papier et al., 2016) and kidney disease (Thawornchaisit et al., 2015), are all increasing. Instant food is replacing traditional diets (Rimpeekool et al., 2017) as people migrate from rural to urban environments. Lifestyles are changing, physical activity is declining (Lim, Kjellstrom, et al., 2009) and alcohol intake is rising (Wakabayashi et al., 2015). In addition, people drink more soft drinks and other sugar sweetened beverages (Rimpeekool et al., 2017) which results in population weight gain (Lim et al., 2014) and diabetes (Papier, D'Este, et al., 2017). Although the trend of cigarette smoking in Thai men is declining its prevalence still exceeds $20 \%$ overall and reaches $40 \%$ in some groups (Kamsa-ard, 2013; Zhao, Pachanee, et al., 2015). Regular smoking is directly associated with a higher incidence of hypertension (Thawornchaisit et al., 2013c). The traditional expectation that females do not smoke continues to powerfully protect half of the population from tobacco related illness, including hypertension. As well, economic growth is leading to a growing proportion of people with a higher education attainment which also protects against hypertension (Thawornchaisit et al., 2013a). Educated people tend to have healthier diets with less instant food (Rimpeekool et al., 2017). In our study, ageing was associated with an increased risk of hypertension which was similar to other longitudinal studies in the US (He, Klag, Appel, Charleston, \& Whelton, 1998), Korea (J. Kim et al., 2006; J. H. Lee et al., 2011), Portugal (Pereira et al., 2012) and South Asia (Prabhakaran et al., 2017) as well as cross-sectional studies in the US (Ong, Cheung, Man, Lau, \& Lam, 2007; Owolabi, Goon, Adeniyi, \& Seekoe, 2017), Morocco (Berraho et al., 2012), Jordan (Mubarak, Froelicher, Jaddou, \& Ajlouni, 2008), India (Kishore, Gupta, Kohli, \& Kumar, 2016), China (Gao et al., 2013), and Korea (Choi, Kim, \& Kang, 2017).

In our cohort, at the 8-year time point sex continues to have a big influence on hypertension incidence just as we noted at the 4-year follow up, but the still doubled rate among men was no longer statistically significant due to loss of statistical power. In another cohort study from USA, the male risk was significantly higher (He et al., 1998). In India a higher male rate was found but it was not significant (Prabhakaran et al., 2017). In a Korean cohort females had a higher risk but the sex differential was not significant (J. H. Lee et al., 2011). Men had a significantly higher risk of hypertension than women in cross-sectional studies in the US (Owolabi et al., 2017), China (Gao et al., 2013; Huang et al., 2017; Liu et al., 2014; Yang et al., 2015), Brazil (Vinholes et al., 2017) and Malaysia (Abdul-Razak et al., 2016). In contrast, other cross-sectional studies have reported no sex difference in the US (Ong et al., 2007), Malaysia (Rashid \& Azizah, 2011), and Morocco (Berraho et al., 2012) and in Pakistan females had higher rates (Shafi \& Shafi, 2017).

Socioeconomic status, especially education attainment and household assets, was inversely associated with incident hypertension. A similar result for education attainment was noted in longitudinal studies in Portugal (Pereira et al., 2012), and South Asia (Prabhakaran et al., 2017). Supportive findings were found with cross-sectional studies in Korea (Choi et al., 2017; C. S. Park et al., 2016), Malaysia (Abdul-Razak et al., 2016), China (Gao et al., 2013; Ruixing et al., 2008), Brazil (Silva, Petroski, \& Peres, 2012), India (Kishore et al., 2016) and the US (Ong et al., 2007). In contrast, education had no influence on blood pressure in a 7-year longitudinal study in the US (He et al., 1998) or in cross-sectional studies in United Arab Emirates (Shah et al., 2015) and Morocco (Berraho et al., 2012).

Household assets indicate family income and inverse influence of this variable on hypertension had been found in many studies including cross-sectional reports in the US (Kaplan, Huguet, Feeny, \& McFarland, 2010; Owolabi et al., 2017) and Brazil (Silva et al., 2012). In contrast, income had no effect on hypertension incidence in a 7-year prospective study in the US (He et al., 1998) and in cross-sectional studies in United Arab Emirates (Shah et al., 2015) and Malaysia (Rashid \& Azizah, 2011). But income had a direct association with hypertension in Ghana (Addo, Smeeth, \& Leon, 2009). The association of income and hypertension in Thailand is similar to that in 
high-income developed countries.

BMI was directly associated with the incidence of hypertension in our TCS. Similar findings were reported from other follow up studies spanning 10 years in Korea (Y. Kim \& Jee, 2017), 46 years in the US (Shihab et al., 2012), 5 years in China (Ren et al., 2016), 4 years in Portugal (Pereira et al., 2012) and 11 years in Norway (Droyvold, Midthjell, Nilsen, \& Holmen, 2005). Supportive cross-sectional results have been reported from the US (Hajjar \& Kotchen, 2003; Ong et al., 2007), Morocco (Berraho et al., 2012), Jordan (Mubarak et al., 2008), India (Kishore et al., 2016) and China (Gao et al., 2013; Liu et al., 2014; Yang et al., 2015).

The sympathetic nervous system plays a major role in obesity-induced hypertension. Weight gain stimulates norepinephrine, and probably leptin, release leading to sodium retention and elevated blood pressure (Masuo, Mikami, Ogihara, \& Tuck, 2000). Activation of the renin-angiotensin system of the kidney may also be an important factor in linking obesity and elevated blood pressure (Hall, Brands, Hildebrandt, Kuo, \& Fitzgerald, 2000). Higher BMI was related to a significantly higher risk of hypertension and overweight accounted for 11-25 per cent of population attributable risk (PAR) in the human population (Geleijnse, Grobbee, \& Kok, 2005). A study of Chinese, Filipinos and Americans (Colin Bell, Adair, \& Popkin, 2002) showed that higher BMI was associated with a higher prevalence of hypertension in all ethnic groups,

We found that planned exercise had a substantial protective effect on the incidence of hypertension. Our data showed that LPPA had an inverse relationship with the risk of developing hypertension in Thai adults. Similar findings were reported from prospective studies in Korea (J. Kim et al., 2006; Y. Kim \& Jee, 2017) and a cross-sectional study in Iran (Tabrizi, Sadeghi-Bazargani, Farahbakhsh, Nikniaz, \& Nikniaz, 2016). As a corollary, physical inactivity would be expected to increase hypertension risk and indeed such inactivity was found to account for 5-13 per cent PAR for hypertension in the human population (Geleijnse et al., 2005). Daily walking for at least 30 minutes (Shah et al., 2015) and leisure time physical activity (Silva et al., 2012) significantly lowers the risk of hypertension. However, longitudinal studies in Portugal (Pereira et al., 2012), Korea (J. H. Lee et al., 2011), South Asia (Prabhakaran et al., 2017) and the US (He et al., 1998) reported that physical activity had no influence on the risk of hypertension. The evidence linking exercise to hypertension protection continues to accumulate without perfect agreement and further studies will be needed to clarify the relationships.

In our study, diabetes mellitus strongly associated with the incidence of hypertension as reported in a previous longitudinal study in South Asia (Prabhakaran et al., 2017) and in cross-sectional studies in the US (Owolabi et al., 2017), Pakistan (Shafi \& Shafi, 2017), Morocco (Berraho et al., 2012), Jordan (Mubarak et al., 2008) and China (Gao et al., 2013; Liu et al., 2014). In two of these studies duration of diabetes was positively associated with incidence of hypertension (Berraho et al., 2012; Mubarak et al., 2008). In other diabetes studies, participants with poor blood sugar control had elevated haemoglobin A1c, as well as significantly more hypertension (Salman \& Al-Rubeaan, 2009) and microvascular complications (Stratton et al., 2000). Each 1\% reduction in A1c reduced the risk of microvascular complications by $37 \%$.

Our data on lipids show a strong association of self-reported hyperlipidemia and hypertension, as also noted in longitudinal studies in the US (Halperin et al., 2006; Sesso, Buring, Chown, Ridker, \& Gaziano, 2005) and in Finland (Laaksonen et al., 2008) and cross-sectional studies in China (Gao et al., 2013; Li et al., 2008; Liu et al., 2014; Yang et al., 2015) and India (Kishore et al., 2016). High cholesterol associated with hypertension in prospective studies covering 11 years in American women (Sesso et al., 2005) and 14 years in American men (Halperin et al., 2006). Similar findings emerged from cross-sectional studies in India (Kishore et al., 2016) and China (Yang et al., 2015). In addition, hypertriglyceridemia significantly increased the risk of hypertension in a longitudinal study in Finland (Laaksonen et al., 2008) and in a cross-sectional study in China (Yang et al., 2015). However, such a link was not found in cross-sectional analyses in India (Kishore et al., 2016) or a 5-year longitudinal study in Korea (J. H. Lee et al., 2011). An 11-year follow up study in women (Sesso et al., 2005) and a 7-year follow up in men (Laaksonen et al., 2008) reported that low-density lipoprotein cholesterol (LDL) directly associated with an increased risk of hypertension. However, high-density lipoprotein cholesterol (HDL) was a protective factor in American women (Sesso et al., 2005), American men (Halperin et al., 2006) and Finish men (Laaksonen et al., 2008) but not in Korea adults (J. H. Lee et al., 2011).

Kidney disease (KD) has a strong connection to hypertension incidence, as has been noted many times including in cross-sectional studies in Pakistan (Shafi \& Shafi, 2017), Czech Republic (Jancova et al., 2008) and the US (Kalaitzidis et al., 2009). The prevalence of HTN in patients with renal insufficiency was significantly higher than that in patients without renal insufficiency, which depended on the type of nephropathy and the degree of renal failure (Ridao et al., 2001). The activation of the renin-angiotensin system (RAS) is an important factor contributing to the pathogenesis of hypertension in KD by stimulating the sympathetic nervous system 
(Augustyniak, Tuncel, Zhang, Toto, \& Victor, 2002; Vaughan, Carey, Ayers, \& Peach, 1979; Weidmann, Maxwell, Lupu, Lewin, \& Massry, 1971).

In our cohort, cigarette smokers were at a higher risk of developing hypertension. This result was supported by various reports such as a large longitudinal study in American women showing that more than 15 cigarettes per day significantly increased risk of hypertension (Bowman, Gaziano, Buring, \& Sesso, 2007) and an 11-year study of Finish men showing more than 20 cigarettes smoking per day strongly associated with risk of developing hypertension (Niskanen et al., 2004). However, longitudinal studies in Portugal (Pereira et al., 2012) and South Asia (Prabhakaran et al., 2017) and cross-sectional studies in Iran (Tabrizi et al., 2016), United Arab Emirates (Shah et al., 2015) and Brazil (Silva et al., 2012) did not connect cigarette consumption and incidence of hypertension. Indeed, cigarette smoking significantly decreased risk of hypertension in cross-sectional studies in Brazil (Berraho et al., 2012) and China (Li et al., 2008). The effect of cigarette smoking on reduced risk of hypertension may be as a result of smoking decreased body weight. In women, light cigarette smoking (1-9 cigarettes/day) had a lower BMI and blood pressure than those non-smokers (Primatesta, Falaschetti, Gupta, Marmot, \& Poulter, 2001). Furthermore, a 4-year follow up study in Korea (D. H. Lee, Ha, Kim, \& Jacobs, 2001) reported that cigarette smoking cessation significantly increased risk of hypertension which may associate with weight gain in smoking cessation (Niskanen et al., 2004). Data from our cohort show a rapid decline in excess mortality among those who quit smoking suggesting that regardless of the effect on hypertension ex-smokers experience a net advantage compared to those who continue smoking (Zhao, Pachanee, et al., 2015).

Regular consumption of instant food which contains high salt and carbohydrate strongly increased risk of developing hypertension. Consistent with previous studies reporting high salt diet $(\mathrm{NaCl})$ increased risk of hypertension (Tabrizi et al., 2016) and aggravated extant high blood pressure (Alam \& Johnson, 1999; Chidambaram et al., 2014). Instant noodle consumers are known to be at risk of high intake of energy, fat, and sodium (J. Park, Lee, Jang, Chung, \& Kim, 2011), all of which increase the risk of hypertension. Yokokawa et al showed that daily salt consumption in Thailand averaged 9.9 gram per day which is about twice of daily salt intake ( $5 \mathrm{gram} /$ day) recommended by World Health Organization (Yokokawa et al., 2016). In a Western population (Geleijnse et al., 2005) has demonstrated that higher salt consumption relates to significantly higher risk of hypertension, accounting for 9-17 per cent PAR in the human population.

We found that soft drink intake more than one time per week increased risk of hypertension and this result was supported by a previous cross-sectional study (Song et al., 2017). Sugars and sugar-sweetened beverages (SSB), especially glucose and fructose, associated with an increase systolic and diastolic blood pressure (Brown et al., 2011; Souza Bda, Cunha, Pereira, \& Sichieri, 2016). Reduced consumption of SSB significantly associated with reduced systolic and diastolic blood pressure (Chen et al., 2010). In a prospective study higher consumption of SSB associated with increased body weight and diabetes risk (Schulze et al., 2004) both of which are important risks for hypertension. In a related report from the TCS the SSB intake associated directly with diabetes mellitus incidence (Papier, Jordan, et al., 2017). The direct associations reported here for SSB/fructose intake and hypertension are consistent with hypothesized effects on the uric acid pathway (Brown et al., 2011). For instance, fructose consumption may lead to increased serum uric acid which may influence blood pressure by reducing levels of nitric oxide, a potent vasodilator (Nakagawa et al., 2006). Sugar consumption has also been associated with enhanced sympathetic nervous system activity and sodium retention (Rowe et al., 1981). Recent evidence has linked SSB to diabetes directly without requiring excess weight and this information should be of interest to policy makers for SSB regulation (Papier, Jordan, et al., 2017).

Our study has certain advantages. It is the largest prospective study in Thailand evaluating most health risk factors for hypertension. The study participants live all over Thailand and represent people well socio-demographically (Seubsman et al., 2012) even though they are younger and have a higher education attainment than average for general population. A previous 4-year follow up study in 2009 (Thawornchaisit et al., 2013c) and associated 2005 baseline cross-sectional study (Thawornchaisit et al., 2013a) identified risk factors for hypertension in Thai people. But the results of this 8-year study will be more accurate despite losing some statistical power due to cohort attrition. Worldwide many studies report on risks for hypertension however socio-economic, lifestyle and behaviour risks of each country are not similar. The results from our cohort will predict the trend of hypertension in Thailand.

However, our study has limitations. There may be recall and reporting errors. But our study of the validity of self-reported weight and height in open university students found that the accuracy was quite acceptable (Lim, Seubsman, \& Sleigh, 2009). Also we performed a validation study of self-reported hypertension using a random age-sex matched sample of the cohort reporting hypertension $(n=240)$ or no hypertension $(n=240)$ (Thawornchaisit 
et al., 2013b). We found that the sensitivity was high $(82 \%)$ and that the negative reports were usually accurate (86\%). Also published is our study validating self-reported diabetes (Papier, Jordan, et al., 2017). We also investigated the impact of the non-responses to the 2009 follow-up and found small effects with under-representation of young urban men; this missing group would have a minor influence on our results and would not be expected to have a high rate of incident hypertension (Thinkhamrop, Seubsman, \& Sleigh, 2011). The findings from our study are robust and represent well the future trends of health risk transition in middle-income Thailand and in similar ASEAN countries.

In conclusion, older age, obesity and underlying morbidity due to diabetes, high blood lipids and kidney disease strongly increased risk of incident hypertension while physical inactivity, cigarette smoking, instant food and soft-drink consumption had a moderate effect. Education attainment and household assets had an inverse effect on risk of hypertension development. Sex, living with partner, sedentary lifestyle, alcohol drinking and the consumption of fruit and vegetables had no influence on hypertension. Prevention should focus on more consumption of healthy food with low fat, sugar and salt consumption, more physical exercise and less instant and soft-drink consumption. Thais should be encouraged to maintain normal BMI. A reduction of sugar consumption should be a national policy by limiting the concentration of sugar in soft-drink, ready-to-eat and industrial foods. Smoking cessation should be promoted for Thais especially men.

\section{Acknowledgements}

This study was supported by the International Collaborative Research Grants Scheme, with joint grants from the Wellcome Trust UK (GR071587MA) and the Australian NHMRC (268055), and by a global health grant from the NHMRC (585426). We thank the Thai Cohort Study team at Sukhothai Thammathirat Open University (STOU) and the STOU students participating in the study. We also thank Dr Bandit Thinkamrop and his data team from Khon Kaen University for guiding us successfully through data processing.

\section{Thai Cohort Study Team}

Thailand: Jaruwan Chokhanapitak, Suttanit Hounthasarn, Suwanee Khamman, Daoruang Pandee, Suttinan Pangsap, Tippawan Prapamontol, Janya Puengson, Sam-ang Seubsman, Boonchai Somboonsook, Nintita Sripaiboonkij, Pathumvadee Somsamai, Prasutr Thawornchaisit, Duangkae Vilainerun, Wanee Wimonwattanaphan, Cha-aim Pachanee, Arunrat Tangmunkongvorakul, Benjawan Tawatsupa, Wimalin Rimpeekool.

Australia: Chris Bain, Emily Banks, Cathy Banwell, Bruce Caldwell, Gordon Carmichael, Tarie Dellora, Jane Dixon, Sharon Friel, David Harley, Matthew Kelly, Tord Kjellstrom, Lynette Lim, Anthony McMichael, Tanya Mark, Adrian Sleigh, Lyndall Strazdins, Vasoontara Yiengprugsawan, Susan Jordan, Janneke Berecki-Gisolf, Rod McClure.

\section{Ethical Considerations}

Ethical approval was obtained from Sukhothai Thammathirat Open University Research and Development Institute (protocol 0522/10) and the Australian National University Human Research Ethics Committee (protocol 2004344 and 2009570). Informed, written consent was obtained from all participants.

\section{Competing Interests Statement}

The authors declare that they have no competing or potential conflicts of interest.

\section{References}

Abdul-Razak, S., Daher, A. M., Ramli, A. S., Ariffin, F., Mazapuspavina, M. Y., Ambigga, K. S., . . Investigators, R. (2016). Prevalence, awareness, treatment, control and socio demographic determinants of hypertension in Malaysian adults. BMC Public Health, 16, 351. https://doi.org/10.1186/s12889-016-3008-y

Addo, J., Smeeth, L., \& Leon, D. A. (2009). Socioeconomic position and hypertension: A study of urban civil servants in Ghana. $J$ Epidemiol Community Health, 63(8), 646-650. https://doi.org/10.1136/jech.2008.081828

Aekplakorn, W., Abbott-Klafter, J., Khonputsa, P., Tatsanavivat, P., Chongsuvivatwong, V., Chariyalertsak, S., .. . Lim, S. S. (2008). Prevalence and management of prehypertension and hypertension by geographic regions of Thailand: the Third National Health Examination Survey, 2004. J Hypertens, 26(2), 191-198. https://doi.org/10.1097/HJH.0b013e3282f09f57

Aekplakorn, W., Chariyalertsak, S., Kessomboon, P., Sangthong, R., Inthawong, R., Putwatana, P., ... Thai National Health Examination Survey, I. V. S. G. (2011). Prevalence and management of diabetes and 
metabolic risk factors in Thai adults: the Thai National Health Examination Survey IV, 2009. Diabetes Care, 34(9), 1980-1985. https://doi.org/10.2337/dc11-0099

Aekplakorn, W., Inthawong, R., Kessomboon, P., Sangthong, R., Chariyalertsak, S., Putwatana, P., \& Taneepanichskul, S. (2014). Prevalence and trends of obesity and association with socioeconomic status in Thai adults: National Health Examination Surveys, 1991-2009. $J$ Obes, 2014, 410259. https://doi.org/10.1155/2014/410259

Aekplakorn, W., Sangthong, R., Kessomboon, P., Putwatana, P., Inthawong, R., Taneepanichskul, S., . . the National Health Examination Survey, I. V. s. g. (2012). Changes in prevalence, awareness, treatment and control of hypertension in Thai population, 2004-2009: Thai National Health Examination Survey III-IV. $J$ Hypertens, 30(9), 1734-1742. https://doi.org/10.1097/HJH.0b013e3283568158

Alam, S., \& Johnson, A. G. (1999). A meta-analysis of randomised controlled trials (RCT) among healthy normotensive and essential hypertensive elderly patients to determine the effect of high salt $(\mathrm{NaCl})$ diet of blood pressure. J Hum Hypertens, 13(6), 367-374. https://doi.org/10.1038/sj.jhh.1000817

Apinonkul, B., Soonthorndhada, K., Vapattanawong, P., Jagger, C., \& Aekplakorn, W. (2016). Regional and Gender Differences in Years with and without Mobility Limitation in the Older Population of Thailand. PLoS One, 11(5), e0153763. https://doi.org/10.1371/journal.pone.0153763

Augustyniak, R. A., Tuncel, M., Zhang, W., Toto, R. D., \& Victor, R. G. (2002). Sympathetic overactivity as a cause of hypertension in chronic renal failure. $J$ Hypertens, 20(1), 3-9. https://doi.org/10.1097/00004872-200201000-00002

Australian Institute of Health and Welfare. (2003). The Active Australia Survey: a guide and manual for implementation, analysis and reporting Canberra. AIHW.

Banks, E., Lim, L., Seubsman, S. A., Bain, C., \& Sleigh, A. (2011). Relationship of obesity to physical activity, domestic activities, and sedentary behaviours: cross-sectional findings from a national cohort of over 70,000 Thai adults. BMC Public Health, 11, 762. https://doi.org/10.1186/1471-2458-11-762

Berraho, M., El Achhab, Y., Benslimane, A., El Rhazi, K., Chikri, M., \& Nejjari, C. (2012). Hypertension and type 2 diabetes: a cross-sectional study in Morocco (EPIDIAM Study). Pan Afr Med J, 11, 52.

Bowman, T. S., Gaziano, J. M., Buring, J. E., \& Sesso, H. D. (2007). A prospective study of cigarette smoking and risk of incident hypertension in women. $J$ Am Coll Cardiol, 50(21), 2085-2092. https://doi.org/10.1016/j.jacc.2007.08.017

Brown, I. J., Stamler, J., Van Horn, L., Robertson, C. E., Chan, Q., Dyer, A. R., . . Blood Pressure Research, G. (2011). Sugar-sweetened beverage, sugar intake of individuals, and their blood pressure: international study of macro/micronutrients and blood pressure. Hypertension, 57(4), 695-701. https://doi.org/10.1161/HYPERTENSIONAHA.110.165456

Chen, L., Caballero, B., Mitchell, D. C., Loria, C., Lin, P. H., Champagne, C. M., .. . Appel, L. J. (2010). Reducing consumption of sugar-sweetened beverages is associated with reduced blood pressure: a prospective study $\begin{array}{llll}\text { among United States adults. Circulation, 121(22), 2398-2406. } & \text {. }\end{array}$ https://doi.org/10.1161/CIRCULATIONAHA.109.911164

Chidambaram, N., Sethupathy, S., Saravanan, N., Mori, M., Yamori, Y., Garg, A. K., \& Chockalingam, A. (2014). Relationship of sodium and magnesium intakes to hypertension proven by 24-hour urianalysis in a South Indian population. J Clin Hypertens (Greenwich), 16(8), 581-586. https://doi.org/10.1111/jch.12361

Choi, H. M., Kim, H. C., \& Kang, D. R. (2017). Sex differences in hypertension prevalence and control: Analysis of the 2010-2014 Korea National Health and Nutrition Examination Survey. PLoS One, 12(5), e0178334. https://doi.org/10.1371/journal.pone.0178334

Cifkova, R., Fodor, G., \& Wohlfahrt, P. (2016). Changes in Hypertension Prevalence, Awareness, Treatment, and Control in High-, Middle-, and Low-Income Countries: An Update. Curr Hypertens Rep, 18(8), 62. https://doi.org/10.1007/s11906-016-0669-y

Colin Bell, A., Adair, L. S., \& Popkin, B. M. (2002). Ethnic differences in the association between body mass index and hypertension. Am J Epidemiol, 155(4), 346-353. https://doi.org/10.1093/aje/155.4.346

Collaborators, G. B. D. R. F., Forouzanfar, M. H., Alexander, L., Anderson, H. R., Bachman, V. F., Biryukov, S., . . Murray, C. J. (2015). Global, regional, and national comparative risk assessment of 79 behavioural, environmental and occupational, and metabolic risks or clusters of risks in 188 countries, 1990-2013: a 
systematic analysis for the Global Burden of Disease Study 2013. Lancet, 386(10010), 2287-2323. https://doi.org/10.1016/S0140-6736(15)00128-2

Droyvold, W. B., Midthjell, K., Nilsen, T. I., \& Holmen, J. (2005). Change in body mass index and its impact on blood pressure: a prospective population study. Int $J$ Obes (Lond), 29(6), 650-655. https://doi.org/10.1038/sj.ijo.0802944

Gao, Y., Chen, G., Tian, H., Lin, L., Lu, J., Weng, J., . . Metabolic Disorders Study, G. (2013). Prevalence of hypertension in china: a cross-sectional study. PLoS One, 8(6), e65938. https://doi.org/10.1371/journal.pone.0065938

GBD 2013 Mortality and Causes of Death Collaborator. (2015). Global, regional, and national age-sex specific all-cause and cause-specific mortality for 240 causes of death, 1990-2013: a systematic analysis for the Global Burden of Disease Study 2013. Lancet, 385, 117-171.

Geleijnse, J. M., Grobbee, D. E., \& Kok, F. J. (2005). Impact of dietary and lifestyle factors on the prevalence of hypertension in Western populations. $J$ Hum Hypertens, 19 Suppl 3, S1-4. https://doi.org/10.1038/sj.jhh.1001953

Hajjar, I., \& Kotchen, T. A. (2003). Trends in prevalence, awareness, treatment, and control of hypertension in the United States, 1988-2000. JAMA, 290(2), 199-206. https://doi.org/10.1001/jama.290.2.199

Hall, J. E., Brands, M. W., Hildebrandt, D. A., Kuo, J., \& Fitzgerald, S. (2000). Role of sympathetic nervous system and neuropeptides in obesity hypertension. Braz J Med Biol Res, 33(6), 605-618. https://doi.org/10.1590/S0100-879X2000000600001

Halperin, R. O., Sesso, H. D., Ma, J., Buring, J. E., Stampfer, M. J., \& Gaziano, J. M. (2006). Dyslipidemia and the risk of incident hypertension in men. Hypertension, 47(1), 45-50. https://doi.org/10.1161/01.HYP.0000196306.42418.0e

He, J., Klag, M. J., Appel, L. J., Charleston, J., \& Whelton, P. K. (1998). Seven-year incidence of hypertension in a cohort of middle-aged African Americans and whites. Hypertension, 31(5), 1130-1135. https://doi.org/10.1161/01.HYP.31.5.1130

Huang, G., Xu, J. B., Liu, Y., Liu, Z. H., Zhang, Y. L., Wu, Y. L., . . Zhang, T. J. (2017). Temporal trends in Prevalence, Awareness, Treatment, and Control of Hypertension from 2000 to 2010 in Chengdu, China. Sci Rep, 7(1), 8964. https://doi.org/10.1038/s41598-017-09579-2

Huangfu, X., Zhu, Z., Zhong, C., Bu, X., Zhou, Y., Tian, Y., . . Zhang, Y. (2017). Smoking, Hypertension, and Their Combined Effect on Ischemic Stroke Incidence: A Prospective Study among Inner Mongolians in China. J Stroke Cerebrovasc Dis. https://doi.org/10.1016/j.jstrokecerebrovasdis.2017.06.048

Jancova, E., Vankova, Z., Honsova, E., Lanska, V., Rysava, R., Merta, M., . . Tesar, V. (2008). Prevalence and risk of hypertension in renal disease--data from the Czech Registry of Renal Biopsies. Kidney Blood Press Res, 31(2), 135-142. https://doi.org/10.1159/000126736

Kalaitzidis, R., Li, S., Wang, C., Chen, S. C., McCullough, P. A., \& Bakris, G. L. (2009). Hypertension in early-stage kidney disease: an update from the Kidney Early Evaluation Program (KEEP). Am J Kidney Dis, 53(4 Suppl 4), S22-31. https://doi.org/10.1053/j.ajkd.2008.11.028

Kamsa-ard. (2013). Association between Smoking and Mortality: Khon Kaen Cohort Study, Thailand. Asia Pac J Can Prev, 14(4), 2643-2647. https://doi.org/10.7314/APJCP.2013.14.4.2643

Kanazawa, M., Yoshiike, N., Osaka, T., Numba, Y., Zimmet, P., \& Inoue, S. (2005). Criteria and classification of obesity in Japan and Asia-Oceania. World Rev Nutr Diet, 94, 1-12. https://doi.org/10.1159/000088200

Kaplan, M. S., Huguet, N., Feeny, D. H., \& McFarland, B. H. (2010). Self-reported hypertension prevalence and income among older adults in Canada and the United States. Soc Sci Med, 70(6), 844-849. https://doi.org/10.1016/j.socscimed.2009.11.019

Kearney, P. M., Whelton, M., Reynolds, K., Muntner, P., Whelton, P. K., \& He, J. (2005). Global burden of hypertension: analysis of worldwide data. Lancet, 365(9455), 217-223. https://doi.org/10.1016/S0140-6736(05)17741-1

Kim, J., Kim, E., Yi, H., Joo, S., Shin, K., Kim, J., . . Shin, C. (2006). Short-term incidence rate of hypertension in Korea middle-aged adults. $J$ Hypertens, 24(11), 2177-2182. https://doi.org/10.1097/01.hjh.0000249694.81241.7c 
Kim, Y., \& Jee, H. (2017). Influences of body mass index and physical activity on hypertension and stroke in Korean adult males: 10-year longitudinal study. $J$ Exerc Nutrition Biochem, 21(2), 16-22. https://doi.org/10.20463/jenb.2017.0003

Kishore, J., Gupta, N., Kohli, C., \& Kumar, N. (2016). Prevalence of Hypertension and Determination of Its Risk Factors in Rural Delhi. Int J Hypertens, 2016, 7962595. https://doi.org/10.1155/2016/7962595

Laaksonen, D. E., Niskanen, L., Nyyssonen, K., Lakka, T. A., Laukkanen, J. A., \& Salonen, J. T. (2008). Dyslipidaemia as a predictor of hypertension in middle-aged men. Eur Heart J, 29(20), 2561-2568. https://doi.org/10.1093/eurheartj/ehn061

Lee, D. H., Ha, M. H., Kim, J. R., \& Jacobs, D. R., Jr. (2001). Effects of smoking cessation on changes in blood pressure and incidence of hypertension: a 4-year follow-up study. Hypertension, 37(2), 194-198. https://doi.org/10.1161/01.HYP.37.2.194

Lee, J. H., Yang, D. H., Park, H. S., Cho, Y., Jun, J. E., Park, W. H., . . Investigators, H. Y.-D. D. I. S. (2011). Incidence of hypertension in Korea: 5-year follow-up study. J Korean Med Sci, 26(10), 1286-1292. https://doi.org/10.3346/jkms.2011.26.10.1286

Li, H., Xu, T., Tong, W., Liu, Y., Zhao, L., \& Zhang, Y. (2008). Comparison of cardiovascular risk factors between prehypertension and hypertension in a Mongolian population, Inner Mongolia, China. Circ J, 72(10), 1666-1673. https://doi.org/10.1253/circj.CJ-08-0138

Lim, Banwell, C., Bain, C., Banks, E., Seubsman, S. A., Kelly, M., . . Sleigh, A. (2014). Sugar sweetened beverages and weight gain over 4 years in a Thai national cohort--a prospective analysis. PLoS One, 9(5), e95309. https://doi.org/10.1371/journal.pone.0095309

Lim, Kjellstrom, T., Sleigh, A., Khamman, S., Seubsman, S., Dixon, J., \& Banwell, C. (2009). Associations between urbanisation and components of the health-risk transition in Thailand. A descriptive study of 87,000 Thai adults. Glob Health Action, 2. https://doi.org/10.3402/gha.v2i0.1914

Lim, Seubsman, S., \& Sleigh, A. (2009). Validity of self-reported weight, height, and body mass index among university students in Thailand: Implications for population studies of obesity in developing countries. Popul Health Metr, 7, 15. https://doi.org/10.1186/1478-7954-7-15

Liu, F., Ma, Y. T., Yang, Y. N., Zhen, Y. J., Xie, X., Li, X. M., . . Gao, X. M. (2014). The prevalence of isolated systolic hypertension in adult populations from the Han, Uygur and Kazakh ethnic groups in Xinjiang, China. Blood Press, 23(3), 154-159. https://doi.org/10.3109/08037051.2013.838827

Masuo, K., Mikami, H., Ogihara, T., \& Tuck, M. L. (2000). Weight gain-induced blood pressure elevation. Hypertension, 35(5), 1135-1140. https://doi.org/10.1161/01.HYP.35.5.1135

Mubarak, F. M., Froelicher, E. S., Jaddou, H. Y., \& Ajlouni, K. M. (2008). Hypertension among 1000 patients with type 2 diabetes attending a national diabetes center in Jordan. Ann Saudi Med, 28(5), 346-351. https://doi.org/10.5144/0256-4947.2008.346

Nakagawa, T., Hu, H., Zharikov, S., Tuttle, K. R., Short, R. A., Glushakova, O., . . Johnson, R. J. (2006). A causal role for uric acid in fructose-induced metabolic syndrome. Am J Physiol Renal Physiol, 290(3), F625-631. https://doi.org/10.1152/ajprenal.00140.2005

Neupane, D., McLachlan, C. S., Sharma, R., Gyawali, B., Khanal, V., Mishra, S. R., . . Kallestrup, P. (2014). Prevalence of hypertension in member countries of South Asian Association for Regional Cooperation (SAARC): systematic review and meta-analysis. Medicine (Baltimore), 93(13), e74. https://doi.org/10.1097/MD.0000000000000074

Niskanen, L., Laaksonen, D. E., Nyyssonen, K., Punnonen, K., Valkonen, V. P., Fuentes, R., . . Salonen, J. T. (2004). Inflammation, abdominal obesity, and smoking as predictors of hypertension. Hypertension, 44(6), 859-865. https://doi.org/10.1161/01.HYP.0000146691.51307.84

Ong, K. L., Cheung, B. M., Man, Y. B., Lau, C. P., \& Lam, K. S. (2007). Prevalence, awareness, treatment, and control of hypertension among United States adults 1999-2004. Hypertension, 49(1), 69-75. https://doi.org/10.1161/01.HYP.0000252676.46043.18

Owolabi, E. O., Goon, D. T., Adeniyi, O. V., \& Seekoe, E. (2017). Social epidemiology of hypertension in Buffalo City Metropolitan Municipality (BCMM): cross-sectional study of determinants of prevalence, awareness, treatment and control among South African adults. BMJ Open, 7(6), e014349. https://doi.org/10.1136/bmjopen-2016-014349 
Papier, K., D'Este, C., Bain, C., Banwell, C., Seubsman, S., Sleigh, A., \& Jordan, S. (2017). Consumption of sugar-sweetened beverages and type 2 diabetes incidence in Thai adults: results from an 8-year prospective study. Nutr Diabetes, 7(6), e283. https://doi.org/10.1038/nutd.2017.27

Papier, K., Jordan, S., Bain, C., D'Este, C., Thawornchaisit, P., Seubsman, S., \& Sleigh, A. (2017). Validity of Self-Reported Diabetes in a Cohort of Thai Adults. Glob J Health Sci, 9(7). https://doi.org/10.5539/gjhs.v9n7p1

Papier, K., Jordan, S., D'Este, C., Bain, C., Peungson, J., Banwell, C., . . Sleigh, A. (2016). Incidence and risk factors for type 2 diabetes mellitus in transitional Thailand: results from the Thai cohort study. BMJ Open, 6(12), e014102. https://doi.org/10.1136/bmjopen-2016-014102

Park, C. S., Ha, K. H., Kim, H. C., Park, S., Ihm, S. H., \& Lee, H. Y. (2016). The Association between Parameters of Socioeconomic Status and Hypertension in Korea: the Korean Genome and Epidemiology Study. J Korean Med Sci, 31(12), 1922-1928. https://doi.org/10.3346/jkms.2016.31.12.1922

Park, J., Lee, J. S., Jang, Y. A., Chung, H. R., \& Kim, J. (2011). A comparison of food and nutrient intake between instant noodle consumers and non-instant noodle consumers in Korean adults. Nutr Res Pract, 5(5), 443-449. https://doi.org/10.4162/nrp.2011.5.5.443

Pereira, M., Lunet, N., Paulo, C., Severo, M., Azevedo, A., \& Barros, H. (2012). Incidence of hypertension in a prospective cohort study of adults from Porto, Portugal. BMC Cardiovasc Disord, 12, 114. https://doi.org/10.1186/1471-2261-12-114

Prabhakaran, D., Jeemon, P., Ghosh, S., Shivashankar, R., Ajay, V. S., Kondal, D., . . Narayan, K. M. V. (2017). Prevalence and incidence of hypertension: Results from a representative cohort of over 16,000 adults in three cities of South Asia. Indian Heart J, 69(4), 434-441. https://doi.org/10.1016/j.ihj.2017.05.021

Primatesta, P., Falaschetti, E., Gupta, S., Marmot, M. G., \& Poulter, N. R. (2001). Association between smoking and blood pressure: evidence from the health survey for England. Hypertension, 37(2), 187-193. https://doi.org/10.1161/01.HYP.37.2.187

Putadechakum, S. (2014). Cardiovascular Risk Factors and 10-Year Risk for Coronary Heart Disease in Thai Adults. Int $J$ Sci and Res Pub, 4(5), 1-7.

Rashid, A., \& Azizah, A. (2011). Prevalence of hypertension among the elderly Malays living in rural Malaysia. Australas Med J, 4(6), 283-290. https://doi.org/10.4066/AMJ.2011.660

Ren, Q., Su, C., Wang, H., Wang, Z., Du, W., \& Zhang, B. (2016). Change in Body Mass Index and Its Impact on Incidence of Hypertension in 18-65-Year-Old Chinese Adults. Int J Environ Res Public Health, 13(3). https://doi.org/10.3390/ijerph13030257

Ridao, N., Luno, J., Garcia de Vinuesa, S., Gomez, F., Tejedor, A., \& Valderrabano, F. (2001). Prevalence of hypertension in renal disease. Nephrol Dial Transplant, 16(Suppl 1), 70-73. https://doi.org/10.1093/ndt/16.suppl_1.70

Rimpeekool, W., Kirk, M., Yiengprugsawan, V., Banwell, C., Seubsman, S. A., \& Sleigh, A. (2017). Nutrition label experience and consumption of transitional foods among a nationwide cohort of 42,750 Thai adults. Br Food J, 119(2), 425-439. https://doi.org/10.1108/BFJ-07-2016-0327

Rowe, J. W., Young, J. B., Minaker, K. L., Stevens, A. L., Pallotta, J., \& Landsberg, L. (1981). Effect of insulin and glucose infusions on sympathetic nervous system activity in normal man. Diabetes, 30(3), 219-225. https://doi.org/10.2337/diab.30.3.219

Ruixing, Y., Shangling, P., Shuquan, L., Dezhai, Y., Weixiong, L., Qiming, F., .. . Qinchen, L. (2008). Comparison of hypertension and its risk factors between the Guangxi Bai $\mathrm{Ku}$ Yao and Han populations. Blood Press, 17(5-6), 306-316. https://doi.org/10.1080/08037050802589593

Salman, R. A., \& Al-Rubeaan, K. A. (2009). Incidence and risk factors of hypertension among Saudi type 2 diabetes adult patients: an 11-year prospective randomized study. $J$ Diabetes Complications, 23(2), 95-101. https://doi.org/10.1016/j.jdiacomp.2007.10.004

Schulze, M. B., Manson, J. E., Ludwig, D. S., Colditz, G. A., Stampfer, M. J., Willett, W. C., \& Hu, F. B. (2004). Sugar-sweetened beverages, weight gain, and incidence of type 2 diabetes in young and middle-aged women. JAMA, 292(8), 927-934. https://doi.org/10.1001/jama.292.8.927

Sesso, H. D., Buring, J. E., Chown, M. J., Ridker, P. M., \& Gaziano, J. M. (2005). A prospective study of plasma 
lipid levels and hypertension in women. Arch Intern Med, 165(20), 2420-2427. https://doi.org/10.1001/archinte.165.20.2420

Seubsman, S. A., Lim, L. L., Banwell, C., Sripaiboonkit, N., Kelly, M., Bain, C., \& Sleigh, A. C. (2010). Socioeconomic status, sex, and obesity in a large national cohort of 15-87-year-old open university students in Thailand. J Epidemiol, 20(1), 13-20. https://doi.org/10.2188/jea.JE20090014

Seubsman, S. A., Yiengprugsawan, V., Sleigh, A. C., \& the Thai Cohort Study, T. (2012). A large national Thai Cohort Study of the Health-Risk Transition based on Sukhothai Thammathirat Open University students. ASEAN J Open Distance Learn, 4(1).

Shafi, S. T., \& Shafi, T. (2017). A survey of hypertension prevalence, awareness, treatment, and control in health screening camps of rural central Punjab, Pakistan. J Epidemiol Glob Health, 7(2), 135-140. https://doi.org/10.1016/j.jegh.2017.01.001

Shah, S. M., Loney, T., Sheek-Hussein, M., El Sadig, M., Al Dhaheri, S., El Barazi, I., . . Ali, R. (2015). Hypertension prevalence, awareness, treatment, and control, in male South Asian immigrants in the United Arab Emirates: a cross-sectional study. BMC Cardiovasc Disord, $15, \quad 30$. https://doi.org/10.1186/s12872-015-0024-2

Shihab, H. M., Meoni, L. A., Chu, A. Y., Wang, N. Y., Ford, D. E., Liang, K. Y., . . Klag, M. J. (2012). Body mass index and risk of incident hypertension over the life course: the Johns Hopkins Precursors Study. Circulation, 126(25), 2983-2989. https://doi.org/10.1161/CIRCULATIONAHA.112.117333

Silva, D. A., Petroski, E. L., \& Peres, M. A. (2012). [Prehypertension and hypertension among adults in a metropolitan area in Southern Brazil: population-based study]. Rev Saude Publica, 46(6), 988-998. https://doi.org/10.1590/S0034-89102012000600008

Sleigh, A. C., Seubsman, S. A., \& Bain, C. (2008). Cohort profile: The Thai Cohort of 87,134 Open University students. Int J Epidemiol, 37(2), 266-272. https://doi.org/10.1093/ije/dym161

Song, H. J., Paek, Y. J., Choi, M. K., Yoo, K. B., Kang, J. H., \& Lee, H. J. (2017). Gender Differences in the relationship between carbonated sugar-sweetened beverage intake and the likelihood of hypertension according to obesity. Int J Public Health, 62(5), 573-581. https://doi.org/10.1007/s00038-016-0855-3

Souza Bda, S., Cunha, D. B., Pereira, R. A., \& Sichieri, R. (2016). Soft drink consumption, mainly diet ones, is associated with increased blood pressure in adolescents. $J$ Hypertens, 34(2), 221-225. https://doi.org/10.1097/HJH.0000000000000800

Stratton, I. M., Adler, A. I., Neil, H. A., Matthews, D. R., Manley, S. E., Cull, C. A., . . Holman, R. R. (2000). Association of glycaemia with macrovascular and microvascular complications of type 2 diabetes (UKPDS 35): prospective observational study. BMJ, 321(7258), 405-412. https://doi.org/10.1136/bmj.321.7258.405

Tabrizi, J. S., Sadeghi-Bazargani, H., Farahbakhsh, M., Nikniaz, L., \& Nikniaz, Z. (2016). Prevalence and Associated Factors of Prehypertension and Hypertension in Iranian Population: The Lifestyle Promotion Project (LPP). PLoS One, 11(10), e0165264. https://doi.org/10.1371/journal.pone.0165264

Thawornchaisit, P., de Looze, F., Reid, C. M., Seubsman, S. A., Sleigh, A., \& Thai Cohort Study, T. (2013a). Health-risk factors and the prevalence of hypertension: cross-sectional findings from a national cohort of 87,143 Thai Open University students. Glob J Health Sci, 5(4), 126-141. https://doi.org/10.5539/gjhs.v5n4p126

Thawornchaisit, P., De Looze, F., Reid, C. M., Seubsman, S. A., Sleigh, A., \& Thai Cohort Study, T. (2013b). Validity of self-reported hypertension: findings from the Thai Cohort Study compared to physician telephone interview. Glob J Health Sci, 6(2), 1-11. https://doi.org/10.5539/gjhs.v6n2p1

Thawornchaisit, P., de Looze, F., Reid, C. M., Seubsman, S. A., Sleigh, A. C., \& Thai Cohort Study, T. (2013c). Health risk factors and the incidence of hypertension: 4-year prospective findings from a national cohort of 60569 Thai Open University students. BMJ Open, 3(6). https://doi.org/10.1136/bmjopen-2013-002826

Thawornchaisit, P., de Looze, F., Reid, C. M., Seubsman, S. A., Tran, T. T., Sleigh, A., \& Thai Cohort Study, T. (2015). Health-Risk Factors and the Prevalence of Chronic Kidney Disease: Cross-Sectional Findings from a National Cohort of 87,143 Thai Open University Students. Glob J Health Sci, 7(5), 59-72. https://doi.org/10.5539/gjhs.v7n5p59

Thinkhamrop, K., Seubsman, S., \& Sleigh, A. (2011). Reasons for Non-Response to Mailed Questionnaires - experience of a large Cohort Study in Thailand. KKU J Public Health Res, 4, 73-87. 
Vathesatogkit, P., Woodward, M., Tanomsup, S., Hengprasith, B., Aekplakorn, W., Yamwong, S., \& Sritara, P. (2012). Long-term effects of socioeconomic status on incident hypertension and progression of blood pressure. J Hypertens, 30(7), 1347-1353. https://doi.org/10.1097/HJH.0b013e32835465ca

Vaughan, E. D., Jr., Carey, R. M., Ayers, C. R., \& Peach, M. J. (1979). Hemodialysis-resistant hypertension: control with an orally active inhibitor of angiotensin-converting enzyme. J Clin Endocrinol Metab, 48(5), 869-871. https://doi.org/10.1210/jcem-48-5-869

Vinholes, D. B., Bassanesi, S. L., Chaves Junior, H. C., Machado, C. A., Melo, I. M. F., Fuchs, F. D., \& Fuchs, S. C. (2017). Association of workplace and population characteristics with prevalence of hypertension among Brazilian industry workers: a multilevel analysis. BMJ Open, 7(8), e015755. https://doi.org/10.1136/bmjopen-2016-015755

Wakabayashi, M., McKetin, R., Banwell, C., Yiengprugsawan, V., Kelly, M., Seubsman, S. A., . . Thai Cohort Study, T. (2015). Alcohol consumption patterns in Thailand and their relationship with non-communicable disease. BMC Public Health, 15, 1297. https://doi.org/10.1186/s12889-015-2662-9

Webb, P., \& Bain, C. (2011). Essential Epidemiology: An Introduction for Students and Health Professionals (2 ed.): Cambridge University Press.

Weidmann, P., Maxwell, M. H., Lupu, A. N., Lewin, A. J., \& Massry, S. G. (1971). Plasma renin activity and blood pressure in terminal renal failure. $N$ Engl $J$ Med, 285(14), 757-762. https://doi.org/10.1056/NEJM197109302851401

WHO. (2017). Global Health Risks - World Health Organization. www.who.int/healthinfo/...disease/GlobalHealthRisks_report_part2.pdf.

WorldAtlas. (2017). Leading Causes Of Death In Thailand. www.worldatlas.com/articles/leading-causes-of-death-in-thailand.html.

Yang, G., Ma, Y., Wang, S., Su, Y., Rao, W., Fu, Y., . . Kou, C. (2015). Prevalence and Correlates of Prehypertension and Hypertension among Adults in Northeastern China: A Cross-Sectional Study. Int $J$ Environ Res Public Health, 13(1), 82. https://doi.org/10.3390/ijerph13010082

Yokokawa, H., Yuasa, M., Nedsuwan, S., Moolphate, S., Fukuda, H., Kitajima, T., . . Marui, E. (2016). Daily salt intake estimated by overnight urine collections indicates a high cardiovascular disease risk in Thailand. Asia Pac J Clin Nutr, 25(1), 39-45. https://doi.org/10.6133/apjcn.2016.25.1.22

Zhao, J., Kelly, M., Bain, C., Seubsman, S. A., Sleigh, A., \& Thai Cohort Study, T. (2015). Risk factors for cardiovascular disease mortality among 86866 members of the Thai Cohort Study, 2005-2010. Glob J Health Sci, 7(1), 107-114. https://doi.org/10.5539/gjhs.v7n1p107

Zhao, J., Pachanee, C. A., Yiengprugsawan, V., Seubsman, S. A., Sleigh, A., \& Thai Cohort Study, T. (2015). Smoking, smoking cessation, and 7-year mortality in a cohort of Thai adults. Popul Health Metr, 13, 30. https://doi.org/10.1186/s12963-015-0062-0

\section{Copyrights}

Copyright for this article is retained by the author(s), with first publication rights granted to the journal.

This is an open-access article distributed under the terms and conditions of the Creative Commons Attribution license (http://creativecommons.org/licenses/by/4.0/). 